made inquiries from the several authorities responsible. Reports from the Muckross and Kenmare estates and from the Bourne Vincent Memorial Park state that poaching is negligible and that the stock is being well maintained.-Secretary, F.P.S.

\title{
HARE INVESTIGATION
}

The Mammal Society of the British Isles is starting an investigation into the status of the brown hare, Lepus europaeus, in Britain. In particular it is hoped to record any changes in distribution and numbers which may follow the spread of myxomatosis in rabbits. Presence or absence records will be collected from as many parishes as possible. Experiments in recording the size of hare populations are in progress and should enable some sample censuses to be made in March, 1955. Will those who can help in this investigation please write to Dr. N. W. Moore, The Nature Conservancy, Furzebrook Research Station, Wareham, Dorset.

\section{NOTICE}

\section{Mammals in Britain}

A week-end course for naturalists, arranged by the Department of Extra-Mural Studies, University of Birmingham, 3rd to 5th December, 1954, at Westham House, near Warwick. Inclusive residential fee, 37s. 6d. Programme and full details from Captain Frank Owen, Warden of Westham House, Barford, Near Warwick. 